\title{
Quaternary InGaAsSb Thermophotovoltaic Diodes
}

Michael W. Dashiell, John F. Beausang, Hassan Ehsani, G. J. Nichols, David M. Depoy, Lee R. Danielson, Phil Talamo, Kevin D. Rahner, Edward J. Brown, Steven R. Burger, Patrick M. Fourspring, William F. Topper, Jr., P. F. Baldasaro, Christine A. Wang, Robin K. Huang, Member, IEEE, Michael K. Connors, George W. Turner, Member, IEEE, Zane A. Shellenbarger, Gordon Taylor, Member, IEEE, Jizhong Li, Ramon Martinelli, Member, IEEE, Dmitry Donetski, Member, IEEE, Sergei Anikeev, Gregory L. Belenky, Fellow, IEEE, and Serge Luryi, Fellow, IEEE

\begin{abstract}
In $\mathrm{Ga}_{1-x} \mathrm{As}_{y} \mathrm{Sb}_{1-y}$ thermophotovoltaic (TPV) diodes were grown lattice matched to GaSb substrates by metalorganic vapor phase epitaxy in the bandgap range of $E_{G}=0.5$ to $0.6 \mathrm{eV}$. InGaAsSb TPV diodes, utilizing front-surface spectral control filters, are measured with thermal-to-electric conversion efficiency and power density (PD) of $\eta_{\mathrm{TPV}}=19.7 \%$ and $\mathrm{PD}=0.58 \mathrm{~W} / \mathrm{cm}^{2}$, respectively, for a radiator temperature of $T_{\text {radiator }}=950{ }^{\circ} \mathrm{C}$, diode temperature of $T_{\text {diode }}=27{ }^{\circ} \mathrm{C}$, and diode bandgap of $E_{G}=0.53 \mathrm{eV}$. Practical limits to TPV energy conversion efficiency are established using measured recombination coefficients and optical properties of front surface spectral control filters which for 0.53-eV InGaAsSb TPV energy conversion are $\eta_{\mathrm{TPV}}=28 \%$ and $\mathrm{PD}=0.85 \mathrm{~W} / \mathrm{cm}^{2}$ at the above operating temperatures. The most severe performance limits are imposed by 1$)$ diode open-circuit voltage $\left(V_{\mathrm{OC}}\right)$ limits due to intrinsic Auger recombination and 2) parasitic photon absorption in the inactive regions of the module. Experimentally, the diode $V_{\mathrm{OC}}$ is $15 \%$ below the practical limit imposed by intrinsic Auger recombination processes. Analysis of InGaAsSb diode electrical performance versus diode architecture indicates that $V_{\mathrm{OC}}$ and thus efficiency are limited by extrinsic recombination processes such as through bulk defects.
\end{abstract}

Index Terms-Diodes, indium gallium arsenide antimonide, photovoltaic.

\section{INTRODUCTION}

$\mathbf{L}$ OW-BANDGAP (low- $\left.E_{G}\right)$ thermophotovoltaic (TPV) converters have attracted interest in the field of direct energy conversion due to the potential for efficient electric generation [1]-[3]. The best reported TPV efficiencies, measured at $T_{\text {radiator }}=950{ }^{\circ} \mathrm{C}$ and $T_{\text {diode }}=27{ }^{\circ} \mathrm{C}$, are $\eta_{\mathrm{TPV}}=24 \%$ for $E_{G}=0.6 \mathrm{eV} \mathrm{InGaAs/InP} \mathrm{[4]} \mathrm{and} \eta_{\mathrm{TPV}}=19.7 \%$ for $E_{G}=0.53 \mathrm{eV} \mathrm{InGaAsSb/GaSb}$ diodes [3]. Both systems utilized spectral control filters mounted on the front surface of the

Manuscript received May 16, 2006; revised August 26, 2006. The review of this paper was arranged by Editor P. Panayotatos.

M. W. Dashiell, J. F. Beausang, H. Ehsani, G. J. Nichols, D. M. Depoy, L. R. Danielson, P. Talamo, K. D. Rahner, E. J. Brown, S. R. Burger, P. M. Fourspring, W. F. Topper, Jr., and P. F. Baldasaro are with Lockheed Martin Corporation, Schenectady, NY 12301-1072 USA

C. A. Wang, R. K. Huang, M. K. Connors, and G. W. Turner are with Lincoln Laboratory, Massachusetts Institute of Technology, Lexington, MA 02420-9108 USA.

Z. A. Shellenbarger, G. Taylor, and R. Martinelli are with Sarnoff Corporation, Princeton, NJ 08543-5300 USA.

$\mathrm{J}$. Li is with the Center for Optical Technologies, Lehigh University, Bethlehem, PA 18015 USA.

D. Donetski, S. Anikeev, G. L. Belenky, and S. Luryi are with the State University of New York, Stony Brook, NY 11794-2350 USA.

Color versions of Figs. 1-5 are available online at http://ieeexplore.ieee.org. Digital Object Identifier 10.1109/TED.2006.885087 diode in order to recuperate below bandgap radiation [5], [6]. Quaternary InGaAsSb alloys were investigated because they can be grown lattice matched to GaSb substrates for bandgaps as low as $0.5 \mathrm{eV}$ [7]-[11]; to date, however, the material underperforms compared to ternary InGaAs TPV diodes. This paper summarizes the theory used to predict the practical TPV thermal-to-electric energy conversion efficiency for heat transferred radiatively from a hot-side radiator to a cold-side diode module. Our analysis uses measured minority carrier recombination coefficients to determine the intrinsic limits to $0.53-\mathrm{eV}$ InGaAsSb TPV diode power conversion efficiency and assesses the electronic material quality and architecture (Table I) required to approach these bounds. Fig. 1 shows the architecture of a typical InGaAsSb n-p junction diode investigated during this paper. A TPV module refers to the combination of front surface spectral control filter and the TPV diode or an array of diodes.

\section{TPV EFFICIENCY $\left(\eta_{\text {TPV }}\right)$}

The TPV thermal-to-electric power conversion efficiency $\eta_{\text {TPV }}$ (Table II) is defined as the electrical power output from the TPV module divided by the total thermal power absorbed in the module. The thermal power transferred from the hot ( $\left.T_{\text {radiator }}\right)$ radiator to the cold module $\left(T_{\text {diode }}\right)$ is due to the radiative heat transfer across a vacuum gap. The maximum electrical power from the TPV diode is the product of the open-circuit voltage $\left(V_{\mathrm{OC}}\right)$, the short circuit current $\left(I_{\mathrm{SC}}\right)$, and the fill factor (FF) [12]. Because photons having energies $\left(E<E_{G}\right)$ cannot be converted into electricity, it is convenient to evaluate the overall efficiency as the product of the diode efficiency $\eta_{\text {Diode }}$ and the spectral efficiency $\eta_{\text {Spectral }}$ [1], [3]. The term $\eta_{\text {Diode }}$ quantifies the power conversion efficiency for the above bandgap $\left(E>E_{G}\right)$ thermal radiation absorbed in the diode's active n-p junction area. The term $\eta_{\text {Spectral }}$ quantifies the ratio of the above bandgap radiation absorbed in the active area divided by the total thermal radiation absorbed in the module. The breakdown of these efficiency parameters is given in Table III. The overall expression for TPV thermal-to-electric power conversion efficiency $\eta_{\mathrm{TPV}}$ is

$$
\begin{aligned}
\eta_{\mathrm{TPV}} & =\eta_{\text {Spectral }} \times \eta_{\text {Diode }} \\
& =\frac{V_{\mathrm{OC}} \times I_{\mathrm{SC}} \times \mathrm{FF}}{A_{\text {Total }} \int_{0}^{\infty} \varepsilon_{\mathrm{eff}}^{\text {cavity }} \frac{2 \pi E^{3}}{h^{3} c^{2}\left(e^{\left.E / k T_{\text {radiator }}-1\right)}\right.} d E}
\end{aligned}
$$


TABLE I

Summary of 0.53-eV InGaAsSb ARChitectures and MeAsured Open-Circuit Voltages. * Reported Interface ReCOMBination Velocities Are an AVerage Value of Front and Back Interfaces in the DH Lifetime Structures in Refs. [15]-[17]

\begin{tabular}{|c|c|c|c|c|c|c|c|c|}
\hline $\begin{array}{l}\text { InGaAsSb } \\
\text { Architecture }\end{array}$ & $\begin{array}{l}\text { InGaAsSb } \\
\text { n-type } \\
\text { doping }\end{array}$ & $\begin{array}{l}\mathrm{n} \text {-type } \\
\text { confinement }\end{array}$ & $\begin{array}{c}S_{n} \\
(\mathrm{~cm} / \mathrm{s}) \\
*\end{array}$ & $\begin{array}{l}\text { InGaAsSb } \\
\text { p-type } \\
\text { doping }\end{array}$ & $\begin{array}{l}\text { p-type } \\
\text { confinement }\end{array}$ & $\begin{array}{c}S_{p} \\
(\mathrm{~cm} / \mathrm{s}) \\
*\end{array}$ & BSR & $\begin{array}{l}\mathrm{V}_{\mathrm{OC}} / \mathrm{E}_{\mathrm{gap}} @ \\
2.5 \mathrm{Acm}^{-2}\end{array}$ \\
\hline $\mathrm{n} / \mathrm{p}$ & $1 \times 10^{18} \mathrm{~cm}^{-3}$ & $\mathrm{GaSb}$ & $<<2000$ & $5 \times 10^{16} \mathrm{~cm}^{-3}$ & AlGaAsSb & $\begin{array}{c}700 \\
\end{array}$ & No & $0.60 \pm 0.015$ \\
\hline $\mathrm{n} / \mathrm{p}$ & $1 \times 10^{18} \mathrm{~cm}^{-3}$ & $\mathrm{AlGaAsSb}$ & $<2000$ & $2 \times 10^{17} \mathrm{~cm}^{-3}$ & $\mathrm{AlGaAsSb}$ & $\sim 700$ & No & $0.59 \pm 0.015$ \\
\hline $\mathrm{n} / \mathrm{p}$ & $1 \times 10^{18} \mathrm{~cm}^{-3}$ & $\mathrm{GaSb}$ & $<2000$ & $2 \times 10^{17} \mathrm{~cm}^{-3}$ & $\mathrm{GaSb}$ & $\sim 2000$ & No & $0.59 \pm 0.015$ \\
\hline $\mathrm{p} / \mathrm{n}$ & $1 \times 10^{18} \mathrm{~cm}^{-3}$ & $\mathrm{GaSb}$ & $<2000$ & $2 \times 10^{17} \mathrm{~cm}^{-3}$ & $\mathrm{AlGaAsSb}$ & $\sim 700$ & No & $0.60 \pm 0.015$ \\
\hline $\mathrm{p} / \mathrm{n}$ & $1 \times 10^{18} \mathrm{~cm}^{-3}$ & $\mathrm{GaSb}$ & $<2000$ & $2 \times 10^{17} \mathrm{~cm}^{-3}$ & $\mathrm{AlGaAsSb}$ & $\sim 700$ & Yes & $0.60 \pm 0.015$ \\
\hline $\mathrm{p} / \mathrm{n}$ & $1 \times 10^{18} \mathrm{~cm}^{-3}$ & $\mathrm{GaSb}$ & $<2000$ & $2 \times 10^{17} \mathrm{~cm}^{-3}$ & $\mathrm{AlGaAsSb}$ & $\sim 30$ & No & $0.60 \pm 0.015$ \\
\hline $\mathrm{p} / \mathrm{n}$ & $1 \times 10^{18} \mathrm{~cm}^{-3}$ & $\mathrm{GaSb}$ & $<2000$ & $2 \times 10^{17} \mathrm{~cm}^{-3}$ & $\mathrm{GaSb}$ & $\sim 2000$ & No & $0.55 \pm 0.015$ \\
\hline $\mathrm{p} / \mathrm{n}$ & $1 \times 10^{18} \mathrm{~cm}^{-3}$ & $\mathrm{GaSb}$ & $<2000$ & $4 \times 10^{17} \mathrm{~cm}^{-3}$ & AlGaAsSb & $\sim 700$ & No & $0.58 \pm 0.015$ \\
\hline $\mathrm{p} / \mathrm{n}$ & $1 \times 10^{18} \mathrm{~cm}^{-3}$ & GaSb & $<2000$ & $1 \times 10^{18} \mathrm{~cm}^{-3}$ & $\mathrm{AlGaAsSb}$ & $\sim 700$ & No & $0.59 \pm 0.015$ \\
\hline $\mathrm{p} / \mathrm{n}$ & $1 \times 10^{17} \mathrm{~cm}^{-3}$ & $\mathrm{GaSb}$ & $<2000$ & $2 \times 10^{17} \mathrm{~cm}^{-3}$ & AlGaAsSb & $\sim 700$ & No & $0.58 \pm 0.015$ \\
\hline $\mathrm{p} / \mathrm{n}$ & $2 \times 10^{17} \mathrm{~cm}^{-3}$ & $\mathrm{GaSb}$ & $<2000$ & $2 \times 10^{17} \mathrm{~cm}^{-3}$ & $\mathrm{AlGaAsSb}$ & $\sim 700$ & No & $0.58 \pm 0.015$ \\
\hline $\mathrm{p} / \mathrm{n}$ & $3 \times 10^{17} \mathrm{~cm}^{-3}$ & $\mathrm{GaSb}$ & $<2000$ & $2 \times 10^{17} \mathrm{~cm}^{-3}$ & $\mathrm{AlGaAsSb}$ & $\sim 700$ & No & $0.59 \pm 0.015$ \\
\hline $\mathrm{p} / \mathrm{n}$ & $3 \times 10^{18} \mathrm{~cm}^{-3}$ & $\mathrm{GaSb}$ & $<2000$ & $2 \times 10^{17} \mathrm{~cm}^{-3}$ & $\mathrm{AlGaAsSb}$ & $\sim 700$ & No & $0.59 \pm 0.015$ \\
\hline
\end{tabular}

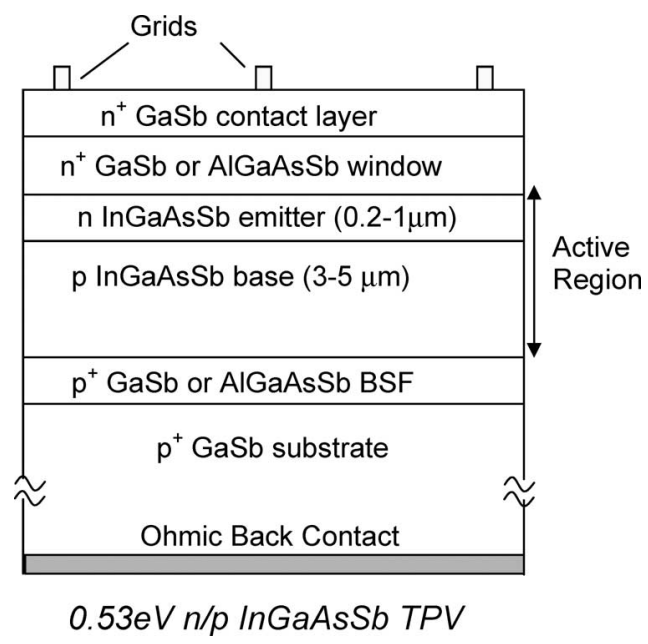

Fig. 1. Schematic of typical $0.53-\mathrm{eV}$ n-p InGaAsSb TPV diode architectures grown on p-type GaSb substrates. p-n diodes having thick p-type emitters were grown on n-type GaSb substrates.

where $E, h, k, c$, and $T_{\text {radiator }}$ are the photon energy, Planck's constant, Boltzmann's constant, the speed of light, and the radiator (hot side) temperature, respectively. The effective cavity emissivity $\varepsilon_{\text {eff }}^{\text {cavity }}$ modifies Planck's spectral distribution to account for nonblackbody emission and absorption in the optical cavity.

While thermodynamic analysis [1], [13], [14] can provide a theoretical maximum to TPV conversion efficiency, nonradiative electronic recombination in the diode and parasitic absorption in the module must be quantified both with experimental material data and mathematical models. This paper uses established semiconductor theory and empirically determined values of InGaAsSb material coefficients [15]-[17] and the optical properties of front surface spectral control filters [5], [6] to determine a practical limit to TPV conversion efficiency applied to the $0.53-\mathrm{eV}$ InGaAsSb TPV material system.

\section{Modeling Assumptions}

This section, along with Tables III and IV, summarizes the TPV diode and spectral modeling assumptions used in this paper.

\section{A. Spectral Control Modeling Assumptions}

Due to optical absorption losses, particularly for photon energies below the diode bandgap, the best reported spectral efficiencies are $\eta_{\text {Spectral }} \sim 80 \%$ for the $0.53-\mathrm{eV}$ bandgap and $T_{\text {radiator }}=950{ }^{\circ} \mathrm{C}$ [5], [6]. For simplicity, spectral performance calculations in this analysis assume a step function reflection profile where the filter reflects $97 \%$ below bandgap photons, reflects $15 \%$ above bandgap photons, and has a $\sim 2 \%$ parasitic absorbance of above bandgap photons in the filter at all incident photon angles. These values project a practical limit to 0.53-eV TPV spectral efficiency based on the optical properties and design optimization studies of front surface filters. The practical limit to spectral efficiency using the approximations detailed in Table III is determined to be $\eta_{\text {Spectral }}=87 \%$.

\section{B. TPV Diode Recombination Models}

The net radiative recombination rate per unit volume, calculated from the Shockley van Roosbroeke (SvR) detailed balance method [18], must be corrected because some of the 
TABLE II

MEASUREd THERMAL-TO-EleCtric EFFICIENCIES FOR 0.53-eV InGaAsSb TPV Diode Modules

\begin{tabular}{|l|l|l|l|}
\hline \hline TPV Diode Parameter & $\mathrm{T}_{\text {diode }} \approx 30^{\circ} \mathrm{C}$ & $\mathrm{T}_{\text {diode }} \approx 50^{\circ} \mathrm{C}$ & $\mathrm{T}_{\text {diode }} \approx 70^{\circ} \mathrm{C}$ \\
\hline \hline Radiator Temperature & $950^{\circ} \mathrm{C}$ & $950^{\circ} \mathrm{C}$ & $950^{\circ} \mathrm{C}$ \\
Average $\mathrm{V}_{\text {OC }}$ per diode (volts) & 0.306 & 0.273 & 0.247 \\
$\mathrm{~J}_{\mathrm{SC}}\left(\right.$ Amps $\left./ \mathrm{cm}^{2}\right)$ & 2.9 & 3 & 3 \\
Module Fill Factor (\%) & 67 & 63 & 60 \\
PD Power Density $\left(\mathrm{W} / \mathrm{cm}^{2}\right)$ & 0.58 & 0.52 & 0.45 \\
$\eta_{\text {TPV }}$ Thermal to Electric Efficiency $(\%)$ & 19.7 & 16.9 & 14.6 \\
\hline
\end{tabular}

TABLE III

Spectral Assumptions Made For $E_{G}=0.53 \mathrm{eV}$ TPV Predictions

\begin{tabular}{|c|c|}
\hline Radiator temperature & $\mathrm{T}_{\mathrm{rad}}=950^{\circ} \mathrm{C}$ \\
\hline Module area & $\mathrm{A}_{2}=0.9 \mathrm{~cm}^{2}$ Active cell area \\
\hline Radiator emissivity & $\varepsilon_{\mathrm{rad} 1}=0.9$ above band gap $>\mathrm{E}_{\mathrm{G}}, \quad \varepsilon_{\mathrm{rad} 2}=0.9$ below band gap $<\mathrm{E}_{\mathrm{G}}$ \\
\hline $\begin{array}{l}\text { TPV diode module } \\
\text { reflectivity }\end{array}$ & $\begin{array}{ll}\mathrm{R}_{1}=0.97<\mathrm{E}_{\mathrm{G}}, \text { active area, } & \mathrm{R}_{2}=0.15>\mathrm{E}_{\mathrm{G}}, \text { active area } \\
\mathrm{R}_{3}=0.97<\mathrm{E}_{\mathrm{G}}, \text { inactive area, } & \mathrm{R}_{4}=0.97>\mathrm{E}_{\mathrm{G}}, \text { inactive area }\end{array}$ \\
\hline Parasitic absorbance & $\mathrm{f}_{\text {parasitic }}=0.02$ (fraction of above bandgap radiation absorbed in filter) \\
\hline $\begin{array}{l}\text { Area weighted module } \\
\text { emissivity at cold side }\end{array}$ & $\begin{array}{l}\varepsilon_{\text {mod } 1}=\frac{A_{2}}{A_{1}}\left(1-R_{2}\right)+\left(1-\frac{A_{2}}{A_{1}}\right)\left(1-R_{4}\right):>\mathrm{E}_{\mathrm{G}}, \\
\varepsilon_{\text {mod } 2}=\frac{A_{2}}{A_{1}}\left(1-R_{1}\right)+\left(1-\frac{A_{2}}{A_{1}}\right)\left(1-R_{3}\right):<\mathrm{E}_{\mathrm{G}},\end{array}$ \\
\hline $\begin{array}{l}\text { Effective emissivity of } \\
\text { radiator / module optical } \\
\text { cavity }\end{array}$ & $\begin{array}{l}\varepsilon_{e f f 1}^{\text {cavity }}=\left(\frac{1}{\varepsilon_{\text {rad } 1}}+\frac{1}{\varepsilon_{\text {mod } 1}}-1\right)^{-1}:>\mathrm{E}_{\mathrm{G}} \\
\varepsilon_{e f f 2}^{\text {cavity }}=\left(\frac{1}{\varepsilon_{\text {rad } 2}}+\frac{1}{\varepsilon_{\bmod 2}}-1\right)^{-1}: \quad<\mathrm{E}_{\mathrm{G}}\end{array}$ \\
\hline $\begin{array}{l}\text { Total heat absorbed in } \\
\text { active region that can be } \\
\text { converted to electricity }\end{array}$ & $\mathrm{P}_{1}=\mathrm{A}_{2} \int_{E_{G}}^{\infty} \frac{\varepsilon_{\text {eff } 1}^{\text {cavity }}\left(1-R_{2}\right)}{\varepsilon_{\bmod 1}} \frac{2 \pi E^{3} d E}{h^{3} c^{2}\left(e^{E / k T_{\text {Rad }}}-1\right)}\left(1-f_{\text {parasitic }}\right)$ \\
\hline $\begin{array}{l}\text { Total heat absorbed in } \\
\text { the cold side module }\end{array}$ & $\mathrm{P}_{2}=A_{1} \int_{E g}^{\infty} \varepsilon_{\text {eff } 1}^{\text {cavity }} \frac{2 \pi E^{3} d E}{h^{3} c^{2}\left(e^{E / k T_{\text {Rad }}}-1\right)}+\mathrm{A}_{1} \int_{0}^{E_{G}} \varepsilon_{\text {eff } 2}^{\text {cavity }} \frac{2 \pi E^{3} d E}{h^{3} c^{2}\left(e^{E / k T_{R a d}}-1\right)}$ \\
\hline Spectral efficiency & $\eta_{\text {spectral }}\left(\mathrm{E}_{\mathrm{G}}=0.53 \mathrm{eV}\right)=\frac{P_{1}}{P_{2}}=87 \%$ \\
\hline TPV efficiency & $\eta_{\mathrm{TPV}}=\frac{V_{O C} \times I_{S C} \times F F}{P_{1}} \times \eta_{\text {Spectral }}=\eta_{\text {Diodel }} \times \eta_{\text {Spectral }}$ \\
\hline
\end{tabular}

light emitted during radiative recombination will be reabsorbed (recycled) in the active region of the TPV diode. The net radiative recombination rate used in the simulations is given by

$$
R_{\mathrm{Rad}}=\frac{B}{\varphi}\left(n p-n_{i}^{2}\right)
$$

where $B n_{i}^{2}$ is the net thermal equilibrium rate of radiative recombination per unit volume calculated via the SvR relation. The photon recycling factor $(\varphi)$ [19], [20] is the inverse ratio of the sum of the photon flux exiting the diode's front and back surfaces to the total number of radiative recombination events occurring within the diode volume (Table IV). The quantities $n$ and $p$ in (2) are the electron and hole carrier densities under illumination, respectively, and $n_{i}$ is the intrinsic carrier density.

Nonradiative recombination is a parasitic loss that includes Auger recombination and recombination via bulk defect and interface states that lie near the center of $E_{G}$ (Shockley-ReadHall (SRH) recombination). The net Auger recombination rate is given by

$$
R_{\mathrm{Aug}}=\left(C_{n} n+C_{p} p\right)\left(n p-n_{i}^{2}\right)
$$


TABLE IV

0.53-eV InGaAsSb Diode PARAMETERS USEd IN Simulations

$\mathrm{T}_{\text {Diode }}$ and $\mathrm{E}_{\mathrm{G}}$

Density of states

Intrinsic electron density

Refractive index

Absorption coefficient

Radiative recombination coefficient [18]

Transmission coefficient for recombination photons internal to diode (forward direction) $[19,20]$

Photon recycling factor $[19,20]$

Auger coefficient

SRH Lifetime

SRV

Electron and hole mobility model [30]

Free carrier absorption in active region

$$
\begin{aligned}
& \mathrm{T}_{300 \mathrm{~K}}=300 \mathrm{~K} / \mathrm{E}_{\mathrm{G}}(300 \mathrm{~K})=0.53 \mathrm{eV} \\
& \mathrm{N}_{\mathrm{C}}=1.5 \times 10^{17} \mathrm{~cm}^{-3}, \quad \mathrm{~N}_{\mathrm{V}}=7 \times 10^{18} \mathrm{~cm}^{-3} \\
& n_{i}^{2}=N_{C} N_{V} \exp \left(-\frac{E_{G}}{k T_{300 K}}\right)=4.5 \times 10^{13} \mathrm{~cm}^{-3}
\end{aligned}
$$

$\mathrm{n}=3.45$

$\alpha(E)=A_{o}\left(E-E_{G}\right)^{0.5}$ where $A_{o}=2.6 \mu m^{-1} e V^{-0.5}$

$B=\frac{1}{n_{i}^{2}} \int_{\theta=0}^{\theta=\pi} \int_{\phi=0}^{\phi=2 \pi} \int_{E=0}^{E=\infty} n^{2} \alpha(E) \frac{\partial \Gamma(E)}{\partial E \partial \phi \partial \theta} \sin \theta d E d \phi d \theta \quad\left(\mathrm{cm}^{3} \cdot \mathrm{s}^{-1}\right)$

where $\frac{\partial \Gamma(E)}{\partial E \partial \phi \partial \theta}=\frac{2 E^{2}}{h^{3} c^{2}}\left(\exp \left(\frac{E}{k T_{300 K}}\right)-1\right)^{-1} \quad\left(\mathrm{~cm}^{2} \cdot \mathrm{s} \cdot \mathrm{eV} \cdot \mathrm{sr}\right)^{-1}$

$\mathrm{B} \approx 1 \times 10^{-10} \mathrm{~cm}^{3} / \mathrm{s}$

$T_{\text {back }}^{\text {forward }}(\theta, E)=\frac{\left(1-R_{\text {back }}\right) R_{\text {front }} \exp \left[\frac{-(z+W) \alpha}{\cos \theta}\right]}{\left(1-R_{\text {front }} R_{b a c k} \exp \left[\frac{-2 \alpha W}{\cos \theta}\right]\right)}$

$T_{\text {front }}^{\text {forward }}(\theta, E)=\left(1-R_{\text {front }}\right) \exp \left[\frac{-z \alpha}{\cos \theta}\right] \frac{R_{\text {front }} R_{\text {back }} \exp \left[\frac{-2 \alpha W}{\cos \theta}\right]}{\left(1-R_{\text {front }} R_{\text {back }} \exp \left[\frac{-2 \alpha W}{\cos \theta}\right]\right)}$

$$
\varphi^{-1}=\frac{\sum_{i} \int_{\text {Surfaces }}^{z=W} \int_{\theta=0}^{\pi / 2} \int_{\phi=0}^{\phi=2 \pi} \int_{E=0}^{E=\infty} n^{2} \alpha(E) \frac{\partial \Gamma(E)}{\partial E \partial \phi \partial \theta} T_{i}(\theta, E) \sin \theta d E d \phi d \theta d z}{\int_{z=0}^{z=W} \int_{\theta=0}^{\theta=\pi} \int_{\phi=0}^{\phi=2 \pi} \int_{E=0}^{E=\infty} n^{2} \alpha(E) \frac{\partial \Gamma(E)}{\partial E \partial \phi \partial \theta} \sin \theta d E d \phi d \theta d z} \quad\left(\mathrm{~cm}^{3} \cdot \mathrm{s}^{-1}\right)
$$

integrate the term in the numerator for both front and back surfaces and for photons originating in both the forward and reverse directions

Ideal BSR: $\varphi_{\mathrm{BSR}=100 \%} \approx 40$, Zero reflection at back $: \varphi_{\text {AbsorbingSubstrate }} \approx 4$

$\mathrm{C}_{\mathrm{n}}=\mathrm{C}_{\mathrm{p}}=2 \times 10^{-28} \mathrm{~cm}^{6} / \mathrm{s}$ unless otherwise indicated

Measured values give $\tau_{\mathrm{SRH}}=0.1$ to $1 \mu$ s for electrons. Intrinsic limit requires $>>1 \mu \mathrm{s}$

$\mathrm{S}_{\mathrm{n}}=\mathrm{S}_{\mathrm{p}}$ varied from $10 \mathrm{~cm} / \mathrm{s}$ to $2000 \mathrm{~cm} / \mathrm{s}[14,15]$

$\mu_{e}=420 \frac{\mathrm{cm}^{2}}{V \cdot s}+\frac{8500}{1+\left(\frac{N_{D}}{5 \times 10^{17} \mathrm{~cm}^{-3}}\right)^{0.7}}$

$$
\mu_{h}=110 \frac{\mathrm{cm}^{2}}{V \cdot s}+\frac{500}{1+\left(\frac{N_{A}}{9 \times 10^{17} \mathrm{~cm}^{-3}}\right)^{0.66}}
$$

Assumed to be negligible and the bulk SRH and surface/interface recombination rates due to electronic defect states near the center of the band gap $\left(R_{\mathrm{SRH}}\right.$ and $\left.R_{\mathrm{SRV}}\right)$ are modeled by

$$
R_{\mathrm{SRH}}=\frac{\left(n p-n_{i}^{2}\right)}{\tau_{n}\left(p+n_{i}\right)+\tau_{p}\left(n+n_{i}\right)}
$$

$$
R_{\mathrm{SRV}}=\frac{S_{n} S_{p}\left(n p-n_{i}^{2}\right)}{S_{n}\left(p+n_{i}\right)+S_{p}\left(n+n_{i}\right)} .
$$

The recombination coefficients $\tau_{n, p}$ (SRH lifetimes), $S_{n, p}$ (effective surface recombination velocities), and $C_{n, p}$ (Auger coefficients) were parametrically varied in the simulations about values reported in minority carrier lifetime studies of InGaAsSb materials [15]-[17]. 


\section{INTRINSIC LIMITATIONS TO TPV DiODE PERFORMANCE}

This section discusses the intrinsic limits to TPV diode opencircuit voltage $V_{\mathrm{OC}}, \mathrm{FF}$, and short circuit current density $I_{\mathrm{SC}}$.

\section{A. Intrinsic Limitations to TPV Diode Open-Circuit Voltage: $V_{\mathrm{OC}}$}

The ideal diode equation expresses the open-circuit voltage as

$$
V_{\mathrm{OC}} \approx \frac{n k T_{\text {diode }}}{q} \ln \left(\frac{I_{\text {light }}-I_{o}}{I_{o}}\right)
$$

where $T_{\text {diode }}$ is the cold-side temperature, $I_{\text {light }}$ is the lightgenerated current, $I_{0}$ is the dark current, $q$ is the electron charge, and $n$ is the ideality factor.

The diode carrier generation/recombination rates that maintain thermal equilibrium with the cold side temperature $T_{\text {diode }}$ determine the diode's dark current $\left(I_{0}\right)$-also known as reverse saturation current [1], [12]-[14]. Bounding the TPV diode active region with a back surface reflector (BSR), rather than an absorbing substrate or back contact, minimizes the radiative component of $I_{0}$ because BSR reduces the number of available photon modes that contribute to the overall equilibrium generation/recombination rates [1] and sets the thermodynamic maximum to $V_{\mathrm{OC}}$. In addition, the ideal BSR will increase the optical path length by a factor of two, enabling a reduction of the volumetric nonradiative recombination processes that are unavoidable in real diodes. In concept, $V_{\mathrm{OC}}$ limitations due to additional extrinsic generation/recombination processes such as bulk SRH defect recombination might be eliminated. However, Auger recombination is a fundamental nonradiative process that can be minimized, but not eliminated, by reducing background carrier densities and absorber thickness. Attempts to reduce Auger recombination limitations to $V_{\mathrm{OC}}$ by reducing background doping will ultimately result in the diode going into high injection. The high injection Auger recombination rate determines the lowest possible nonradiative recombination rate under illuminated conditions and thus sets the intrinsic material limit to $I_{0}$ and $V_{\mathrm{OC}}[21]$.

Using the narrow base approximations from [21], an estimate for the values of the extrinsic coefficients $S_{n, p}$ and $\tau_{n, p}$ required to approach the intrinsic Auger-limited open-circuit voltage can be made. Green [21] determined the $V_{\mathrm{OC}}$ limits as a function of light-generated current density $J_{\text {Light }}$ for absorbing region of background doping $N_{B}$ and thickness $W$ for each of the recombination processes given in (2)-(5). In a "defect-free" material, the optimum background doping $\left(N_{B}\right)$ and the intrinsic Augerlimited $V_{\mathrm{OC}}$ are reached when the illuminated diode enters the high-injection regime. For a p-type absorbing region, the bulk electronic material quality is deemed sufficient to approach this intrinsic limit only when the bulk SRH minority carrier lifetime is greater than the quantity given by

$$
\tau_{p}^{\text {high injection }} \gg\left[q^{2} W^{2} / J_{\text {Light }}^{2}\left(C_{P}+C_{n}\right)\right]^{1 / 3} .
$$

Anikeev et al. [15] report values of the Auger coefficient of $C \approx 2 \times 10^{-28} \mathrm{~cm}^{6} / \mathrm{s}$ in $0.53-\mathrm{eV}$ InGaAsSb. Thus, for lightgenerated currents of $J_{\text {Light }} \approx 3 \mathrm{~A} / \mathrm{cm}^{2}$, the bulk SRH lifetime must be greater than $\tau_{n, p} \gg 1 \mu \mathrm{s}$ in both n-type and p-type InGaAsSb in order to approach the intrinsic Auger-limited $V_{\mathrm{OC}}$. Using the same approach, the front and back surface/ interface recombination velocities need to be $S_{n, p} \leq 100 \mathrm{~cm} / \mathrm{s}$, and the photon recycling factor must be $\varphi \gg 5$ to approach the intrinsic Auger-limited $V_{\mathrm{OC}}$. The last requirement means the InGaAsSb TPV diode requires a BSR in order for the radiative recombination rate to be small compared to the intrinsic Auger recombination rate (see Table IV).

Measured minority carrier lifetimes in p-type double heterostructure (DH) InGaAsSb samples give bulk values of $\tau_{p} \sim 1 \mu \mathrm{s}$ and $S_{p} \approx 700-2000 \mathrm{~cm} / \mathrm{s}$ at the interfaces [15]-[17]. However, unlike p-type InGaAsSb, n-type InGaAsSb exhibits a strong excitation dependence of the carrier lifetime that shows the material is dominated by electrically active SRH-type defects. The excitation dependence makes a precise measurement/model for the SRH lifetime at the relevant light injection levels in n-type InGaAsSb (Te-doped) difficult; however, the preliminary measurements set bounds of $\tau_{n} \geq 0.1 \mu \mathrm{s}$ in n-type InGaAsSb and $S_{n} \leq 2000 \mathrm{~cm} / \mathrm{s}$ at the n-type interfaces. Comparison of the measured n-type and p-type InGaAsSb recombination parameters with those values required to approach the intrinsic Auger limit indicates that the electronic material quality of $0.53-\mathrm{eV}$ InGaAsSb is not sufficient to approach the intrinsic Auger-limited $V_{\mathrm{OC}}$ at these light-generated currents.

\section{B. Intrinsic Limitations to TPV Diode Short Circuit Current and FF}

Unlike $V_{\mathrm{OC}}$, there are no thermodynamic restrictions to the efficiency in which above bandgap photons can be converted to photogenerated electrons. The primary limitations to $I_{\text {light }} \approx$ $I_{\mathrm{SC}}$ are due to parasitic absorption and reflections of above bandgap photons in the spectral control filter and other inactive regions of the TPV module (see Table III). Experimental data for the $0.53-\mathrm{eV}$ InGaAsSb diode indicate that the short circuit current $I_{\mathrm{SC}}$ is not limited by minority carrier recombination in the active region because the minority carrier diffusion lengths are greater than the diode thickness (narrow base), and the effective surface recombination velocities are $S_{n, p}<$ $10^{4} \mathrm{~cm} / \mathrm{s}$. FF also depends on $I_{0}$; however, unlike $V_{\mathrm{OC}}, \mathrm{FF}$ becomes practically limited by series resistances external to the diode active region. Experiments and calculations show that $2 \mathrm{~m} \Omega \cdot \mathrm{cm}^{2}$ is the practical limit to series resistance setting an $\mathrm{FF}$ limit of $\mathrm{FF}=0.74$ for $J_{\mathrm{SC}}=3 \mathrm{~A} / \mathrm{cm}^{2}$.

\section{Numerical Simulations of 0.53-eV InGaAsSb TPV EFFICIENCY AND OUTPUT POWER}

Conversion of the above bandgap thermal radiation into electric power was calculated using PC-1D, a numerical photovoltaic simulator that solves the carrier transport, Poisson, and carrier continuity equations for electrons and holes. Solutions were cross checked using the analytic expressions discussed in this paper and in [12] and [21]. Nonequilibrium electron-hole generation rates in the diode were determined from the 

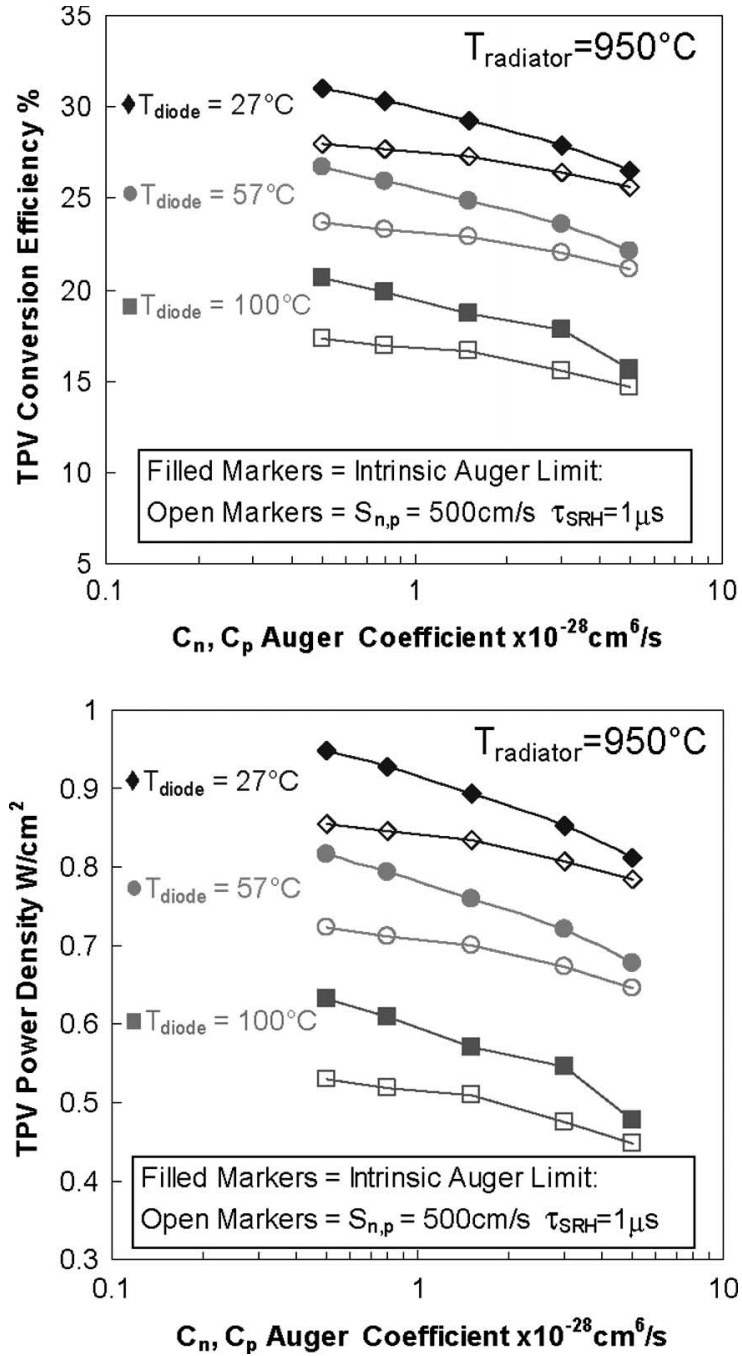

Fig. 2. Intrinsic Auger-limited TPV conversion efficiency $\eta_{\mathrm{TPV}}$ and PD for three different diode temperatures plotted as a function of Auger recombination coefficient and using the spectral properties in Table III. Open markers illustrate the limits for the case having nonnegligible extrinsic recombination losses.

absorbed thermal radiation spectrum transmitted through the front surface spectral control filter into the diode.

Fig. 2(a) and (b) shows the intrinsic efficiency and power density (PD) limits (solid symbols) as a function of the Auger coefficients $C_{n, p}$ for the $0.53-\mathrm{eV}$ TPV diode module having spectral control properties given in Table III, a BSR, negligible defect recombination, and operating at the onset to high level injection. The measured Auger coefficient of $C_{p}=$ $2 \times 10^{-28} \mathrm{~cm}^{6} / \mathrm{s}$ from [15] determines the best estimate to the practical/intrinsic limit for $0.53-\mathrm{eV}$ InGaAsSb TPV. Fig. 2 shows that by raising $T_{\text {diode }}$ from $27{ }^{\circ} \mathrm{C}$ to $100{ }^{\circ} \mathrm{C}$, the practical efficiency limit drops from $\eta_{\mathrm{TPV}}=28 \%$ to $\eta_{\mathrm{TPV}}=18 \%$ due to the strong temperature dependence of the intrinsic carrier density. The open symbols in Fig. 2(a) and (b) show the efficiency and PD limits for 0.53-eV TPV diodes having nonnegligible extrinsic recombination losses $\left(\tau_{n, p}=1 \mu \mathrm{s}\right.$ and $S_{n, p}=500 \mathrm{~cm} / \mathrm{s}$ ), illustrating the stringent material requirements necessary to approach the intrinsic limit.

Fig. 3 shows the simulated diode $V_{\mathrm{OC}}$ as a function of p-type doping $\left(N_{A}\right)$ for the general architecture shown in

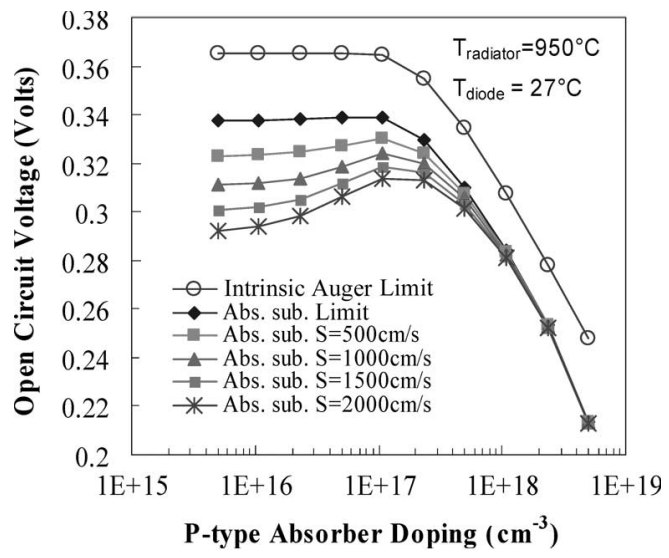

Fig. 3. Simulated open-circuit voltage $V_{\mathrm{OC}}$ for InGaAsSb TPV diode architectures as a function of doping using the recombination parameters listed in Table IV. Each curve corresponds to the architecture described in the legend and in the text.

Fig. 1. The uppermost curve in Fig. 3 corresponds to an architecture having an ideal BSR and two-pass optical path length $(\varphi=40)$ and negligible defect recombination $\left(\tau_{n, p}=\right.$ $\left.10 \mu \mathrm{s}, S_{n, p}=10 \mathrm{~cm} / \mathrm{s}\right)$. The high-level-injection $\left(N_{A} \leq 5 \times\right.$ $10^{16} \mathrm{~cm}^{-3}$ ) Auger recombination rate sets the intrinsic limit to $V_{\mathrm{OC}}$ of $370 \mathrm{mV}$ for the assumed operating temperatures. The second uppermost curve simulates the same InGaAsSb material quality $\left(\tau_{n, p}=10 \mu \mathrm{s}, S_{n, p}=10 \mathrm{~cm} / \mathrm{s}\right)$ but having an absorbing substrate and single-pass optical path length (photon recycling factor $\varphi=4$ ), where the decrease in maximum achievable $V_{\mathrm{OC}}$ to $340 \mathrm{mV}$ is due to the increased radiative dark current and increased thickness to account for the single-pass optical path length. The remaining curves show the degradation in $V_{\mathrm{OC}}$ for increasing extrinsic interface recombination losses $\left(S_{n}=S_{p}=S\right)$, demonstrating that the high-injection regime is no longer optimal for diodes limited by defect recombination and illustrating the severe $V_{\mathrm{OC}}$ degradation. Similar trends were observed when the TPV diode becomes bulk SRH defect limited. The numerical simulations give good agreement with the closed-form analysis in Section IV, stating that the extrinsic parameters must be $\tau_{n, p} \gg 1 \mu \mathrm{s}$ and $S_{n, p} \leq 100 \mathrm{~cm} / \mathrm{s}$ in order to approach the intrinsic Auger limit.

\section{Measured 0.53-eV InGaAsSb TPV Diode ELECTRICAL/OPTICAL CHARACTERISTICS}

Both n-p (thin-emitter) and p-n (thick-emitter) $0.53-\mathrm{eV}$ InGaAsSb DH TPV diodes were fabricated using standard photolithography and metal evaporation [10], [22] having an area of $0.5 \mathrm{~cm}^{2}$. To prevent minority carriers from diffusing to a free semiconductor surface, the diode is passivated with either $\mathrm{GaSb}\left(E_{G} \approx 0.73 \mathrm{eV}\right)$ or AlGaAsSb $\left(E_{G} \approx 1.0 \mathrm{eV}\right)$ window layers [8]-[10], as shown in Fig. 1. Both GaSb and AlGaAsSb back surface fields (BSFs) were investigated to confine minority carriers at the rear of the active diode. A doped $\mathrm{GaSb}$ contact layer was grown subsequent to the window layer to enable ohmic contact formation for the metal contact grid. The influence of parasitic series $\left(r_{\text {series }}<0.005 \Omega \cdot \mathrm{cm}^{2}\right)$ and shunt resistances $\left(r_{\text {series }}>50 \Omega \cdot \mathrm{cm}^{2}\right)$ were negligible near the operating conditions. 


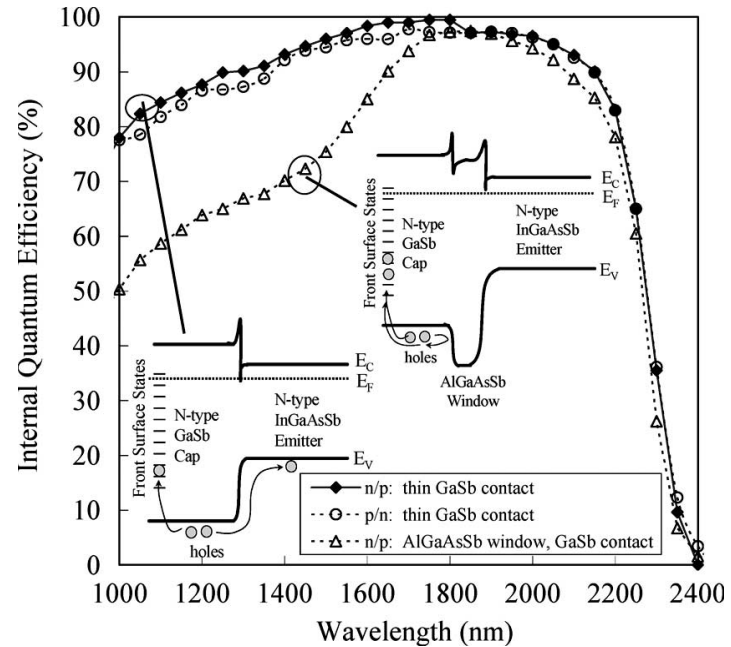

Fig. 4. Measured IQE for 0.53-eV n-p and p-n InGaAsSb diodes having a thin $\mathrm{GaSb}$ window/contact layer and $\mathrm{n}-\mathrm{p}$ diode having $\mathrm{AlGaAsSb}$ window and thick GaSb contact layer. The inset shows a conceptual band diagram of the two window interfaces.

\section{A. Internal Quantum Efficiency (IQE) Measurements of 0.53-eV InGaAsSb TPV Diodes}

Fig. 4 shows the measured $\left(T_{\text {diode }}=27^{\circ} \mathrm{C}\right)$ IQE responses for $\mathrm{n}-\mathrm{p}$ and $\mathrm{p}-\mathrm{n}$ 0.53-eV InGaAsSb TPV diodes. The IQE response is the same for both $\mathrm{n}-\mathrm{p}$ and $\mathrm{p}-\mathrm{n}$ architectures having thin $(<200 \mathrm{~nm}) \mathrm{GaSb}$ window/contact layers (refer to figure legend). The high IQEs between 1600 and $2250 \mathrm{~nm}$ indicate a diffusion length for electrons (holes) in excess of the p-type absorber thickness (thin n-type thickness), which is consistent with simulations and [7] and [10]. The measured IQE degrades at wavelengths below $1600 \mathrm{~nm}$, corresponding to the $\mathrm{GaSb}$ absorption cutoff wavelength [23]. Simulations indicate that a significant fraction of minority carriers generated in the $\mathrm{GaSb}$ contact layer may recombine at the unpassivated GaSbfree surface $\left(S_{\text {surface }} \approx 10^{5} \mathrm{~cm} / \mathrm{s}\right)$ while the remainder may diffuse into the active InGaAsSb region and be collected as photocurrent. The experimental short-wavelength IQE response degraded upon increasing GaSb contact thicknesses, which supports this conclusion.

The third data set in Fig. 4 shows the measured IQE response for an n-p architecture having a thick GaSb contact layer $(>400 \mathrm{~nm})$ and an AlGaAsSb passivating window layer. Severe short-wavelength IQE degradation is observed in this third curve for two reasons. First, the IQE experiences additional degradation at short wavelengths because the GaSb contact layer is more than twice as thick as for the previous two curves. Second, the high $E_{G}$ of the AlGaAsSb layer relative to both the $\mathrm{GaSb}$ contact layer and the $\mathrm{InGaAsSb}$ active region causes it to act as a diffusion barrier to minority carriers generated in the $\mathrm{GaSb}$, which was confirmed by comparing measured responses from two window materials having equivalent $\mathrm{GaSb}$ contact thicknesses. The high $E_{G} \mathrm{AlGaAsSb}$ window between InGaAsSb active region and $\mathrm{GaSb}$ prevents nearly all minority carriers generated in the GaSb contact from diffusing into the active InGaAsSb, which degrades the short-wavelength IQE response compared to using $\mathrm{GaSb}$ windows. The generic band diagrams in the vicinity of the emitter for $n$-p diodes are shown

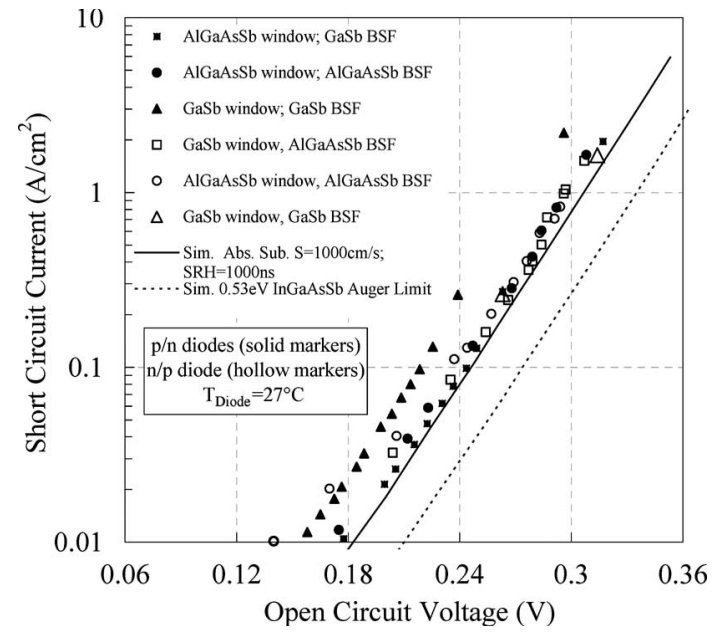

Fig. 5. Plot of measured $V_{\mathrm{OC}}$ versus $J_{\mathrm{SC}}$ data (markers) for various light illuminations for $0.53-\mathrm{eV}$ p-n and n-p InGaAsSb TPV diodes. Inset provides information on whether $\mathrm{GaSb}$ or $\mathrm{AlGaAsSb}$ was used for the passivating window and BSF.

in the inset of Fig. 4, which illustrate these two mechanisms. Note that the effect of this degradation on TPV efficiency and short circuit current is small $(<5 \%$ relative $)$ due to the limited radiation spectrum below $1600 \mathrm{~nm}$ expected from a $950{ }^{\circ} \mathrm{C}$ radiator.

\section{B. Current-Voltage Measurements of n-p and p-n 0.53-eV InGaAsSb TPV Diodes Having GaSb or InGaAsSb DH Confinement}

Fig. 5 shows the open-circuit voltage versus short-circuit current density $\left(V_{\mathrm{OC}}-J_{\mathrm{SC}}\right)$ relation for six $0.53-\mathrm{eV}$ InGaAsSb TPV n-p and p-n diode architectures. The measured $V_{\mathrm{OC}}$ varies logarithmically with $J_{\mathrm{SC}}$, as expected from the ideal diode model, and near-unity ideality $(1.0<n<1.1)$ was observed for all architectures for $J_{\mathrm{SC}}$ values greater than $0.1 \mathrm{~A} / \mathrm{cm}^{2}$. The lowest measured dark currents were $J_{o}=$ $1.5 \times 10^{-5} \mathrm{~A} \cdot \mathrm{cm}^{-2}$ for $\mathrm{p}-\mathrm{n}$ diodes having AlGaAsSb windows and n-p diodes having either GaSb or AlGaAsSb windows. For $J_{\mathrm{SC}}>0.1 \mathrm{~A} / \mathrm{cm}^{2}$, well below our expected operating currents, the current voltage characteristics for both $n-p$ and $p-n$ architectures were insensitive to whether the BSF interface was $\mathrm{GaSb} / \mathrm{InGaAsSb}$ or AlGaAsSb/InGaAsSb. However, p-n diodes with $\mathrm{GaSb}$ window layers have larger room temperature dark currents of $J_{o}=2.5 \times 10^{-5} \mathrm{~A} / \mathrm{cm}^{-2}$, which is attributed to the greater than twofold increase in the front surface recombination velocity. Measured surface recombination velocities at p-type $\mathrm{AlGaAsSb} / \mathrm{InGaAsSb}$ interfaces yielded average measured values of $S_{p} \sim 700 \mathrm{~cm} / \mathrm{s}$, whereas the p-type $\mathrm{InGaAsSb} / \mathrm{GaSb}$ interfaces yield an average value of $S_{p} \sim 2000 \mathrm{~cm} / \mathrm{s}$ [15]-[17]. The dependence of experimental $J_{0}$ for diodes having $\mathrm{p}-\mathrm{GaSb}$ and $\mathrm{p}-\mathrm{AlGaAsSb}$ minority confinement layers provides further insight on the results in [15]-[17]. P-type AlGaAsSb front surface windows reduce $J_{0}$ in p-n diodes compared to p-type $\mathrm{GaSb}$ windows; however, both p-type $\mathrm{AlGaAsSb}$ and $\mathrm{GaSb}$ BSFs yield nearly equivalent $J_{0}$ for n-p diodes. The asymmetry indicates that the p-type AlGaAsSb passivation layer (due to its higher $E_{G}$ ) suppresses the minority carrier diffusion to the free 
surface of the GaSb contact layer; however, its effect (if any) on the number of defect states at the interface does not influence $J_{0}$. Because AlGaAsSb causes a degradation in the IQE, an n-p design using a thin GaSb window may be optimum for both short wavelength photoresponse and high $V_{\mathrm{OC}}$.

Two simulated $V_{\mathrm{OC}}-J_{\mathrm{SC}}$ curves are also shown in Fig. 5. The first simulation (solid line) gives a reasonable agreement (but slightly better) to the measured data by assuming recombination coefficients of $C_{n, p}=2 \times 10^{-28} \mathrm{~cm}^{6} / \mathrm{s}, \tau_{\mathrm{SRH}}=1 \mu \mathrm{s}$, $S_{n, p}=1000 \mathrm{~cm} / \mathrm{s}$, and an absorbing back surface $(\phi=4)$. The second simulation (dotted line) shows the practical limit for a BSR diode architecture $(\phi=40)$ having negligible extrinsic recombination processes, illustrating the potential gains in $V_{\mathrm{OC}}$ with reduction in the extrinsic recombination losses.

\section{Influence of Doping and Architecture on 0.53-eV InGaAsSb TPV Diode Performance}

A summary of the measured $V_{\mathrm{OC}}$ (at $J_{\text {Light }}=J_{\mathrm{SC}} \sim$ $2.5 \mathrm{~A} / \mathrm{cm}^{2}$ ) for various n-type and p-type doping levels and minority carrier confinement layer compositions is shown in Table I. Along with the carrier confinement layers are the corresponding estimates for the interface recombination velocities $S_{n, p}$ from [15]-[17]. The open-circuit voltage was normalized to the bandgap $\left(V_{\mathrm{OC}} / E_{G}\right)$ to account for slight variations in alloy composition observed during the many growth runs performed. Included also in Table I is the $0.53-\mathrm{eV}$ InGaAsSb hybrid BSR device reported in [24], which will have greater photon recycling compared to that of a thick absorbing $\mathrm{GaSb}$ substrate. All diodes listed in Table I had measured FFs of $0.7 \pm 0.02$ and peak IQEs near $\sim 100 \%$.

The only significant change in $V_{\mathrm{OC}} / E_{G}$ was observed for p-n architectures when the effective front surface recombination velocity was increased from $\sim 700$ to $\sim 2000 \mathrm{~cm} / \mathrm{s}$ when using the p-type $\mathrm{GaSb}$ window rather than $\mathrm{AlGaAsSb}$. Table I shows that $V_{\mathrm{OC}} / E_{G}$ remains unchanged for either n-type and p-type doping ranging from mid $10^{16} \mathrm{~cm}^{-3}$ to low $10^{18} \mathrm{~cm}^{-3}$. In addition, $V_{\mathrm{OC}} / E_{G}$ also did not increase beyond a maximum value of $V_{\mathrm{OC}} / E_{G}=0.6$ when the p-type $\mathrm{AlGaAsSb} / \mathrm{InGaAsSb}$ SRV was reduced to $S_{p} \sim 30 \mathrm{~cm} / \mathrm{s}$ by optimizing the interfacial growth conditions [17]. Finally, $V_{\mathrm{OC}}$ did not increase upon thinning the GaSb substrate and incorporating a BSR, although a small increase in long wavelength quantum efficiency was observed due to the increase in the effective optical path length with the BSR [24].

The observed independence of the measured $V_{\mathrm{OC}} / E_{G}$ on InGaAsSb doping levels ranging from mid $10^{16} \mathrm{~cm}^{-3}$ to low $10^{18} \mathrm{~cm}^{-3}$ (changing low injection Auger lifetime), optical boundary conditions (changing photon recycling), and upon reducing the surface recombination velocity to values near $S_{p} \sim 30 \mathrm{~cm} / \mathrm{s}$, as well as the absolute value of the experimental $V_{\mathrm{OC}}$, follows that behavior predicted for a diode whose $V_{\mathrm{OC}}$ is limited by extrinsic material recombination processes. The experimental diode measurements are in agreement with the discussion in Section IV, where the measured values of the extrinsic recombination coefficients $\left(\tau_{n, p}\right.$ and $\left.S_{n}\right)$ do not meet the requirements to obtain the practical limit to $V_{\mathrm{OC}}$. Based upon this, we conclude that extrinsic defect recombina-

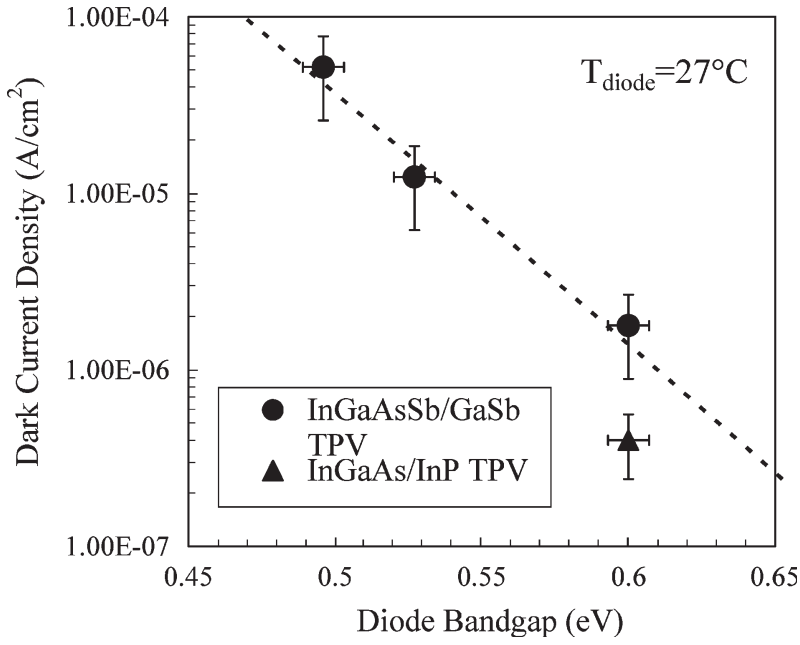

Fig. 6. Measured TPV diode dark current density versus $E_{G}$ for 0.5 - to 0.6-eV InGaAsSb/GaSb and 0.6-eV InGaAs/InP. Experimentally determined dark currents and standard deviations were obtained from batch-processed lots of high-performance TPV diode.

tion mechanisms limit the InGaAsSb diode output voltage and efficiency, in contrast to the conclusions in [7].

\section{0.5- To 0.6-eV InGaAsSb TPV Diodes LatTICE MATCHED TO GaSb}

Bandgap flexibility is an important consideration when choosing a TPV diode material because the optimal diode bandgap depends on both $T_{\text {diode }}$ and $T_{\text {radiator. }}$ Fig. 6 shows the experimental dark current $J_{0}$ versus $E_{G}$ for p-n InGaAsSb TPV diodes grown on GaSb substrates (circles). The ideality factor for all InGaAsSb bandgaps was measured to be $(1.0<$ $n<1.05)$, and all FFs were measured to be FF $=0.70 \pm 0.02$. Measured InGaAsSb dark currents vary proportionally to $J_{0} \alpha \exp \left(-E_{G} / k T_{\text {diode }}\right)$, indicating that 1$)$ the square of the intrinsic carrier density dominates the InGaAsSb dark current characteristics, and thus 2) the electronic material quality is not significantly different over this bandgap range despite the material approaching the miscibility gap [9]. We note that the $0.6-\mathrm{eV}$ InGaAsSb diode probably has a slightly larger front SRV compared to lower bandgaps due to the smaller window band offset [17]. As a qualitative materials comparison, an experimental $J_{0}$ of $0.6-\mathrm{eV} \mathrm{InGaAs/InP}$ diodes, which is representative of $24 \%$ efficient diodes [4], is shown in Fig. 6 (triangle). The dark current for $0.6-\mathrm{eV}$ InGaAs/InP lies well below that of the In$\mathrm{GaAsSb} / \mathrm{GaSb}$ empirical data and fit, suggesting that the ternary InGaAs possesses superior photovoltaic material properties over the quaternary InGaAsSb alloy. High densities of anti-site defects in antimonide-based semiconductors are responsible for the observed high p-type background concentration, and donor anti-site species have also been reported to be associated with deep levels [25]. However, there is no sufficient published defect spectroscopy on low- $E_{G}$ InGaAsSb optoelectronic devices to actually correlate anti-site defects with diode dark current. Further work determining the defect structure in p-type and n-type InGaAsSb and the SRH lifetime in n-type telluriumdoped InGaAsSb would provide additional data. Comparisons of best SRH lifetimes $\left(\tau_{p} \sim 1 \mu \mathrm{s}\right)$ measured in InGaAsSb [15] 
with values of $\left(\tau_{p} \sim 5-14 \mu \mathrm{s}\right)$ reported for GaAs photovoltaic material [26], [27] are further evidence of the significant bulk defect activity in the InGaAsSb alloy system.

\section{Measurements of $0.53-\mathrm{eV}$ InGaAsSb THERMAL-TO-ELECTRIC TPV CONVERSION EFFICIENCY $\left(\eta_{\text {TPV }}\right)$}

The performances of $0.53-\mathrm{eV}$ InGaAsSb TPV diode modules ( 1 and $4 \mathrm{~cm}^{2}$ areas) were measured in a prototypic vacuum test cavity, as described in [3], [28], and [29]. The photonic cavity is prototypical of a flat-plate TPV generator design, where the radiator is a large flat silicon carbide surface. The TPV module was fixed to the top of a copper pedestal to facilitate heat absorption measurements. The thermal-to-electric efficiency in this test was measured as the ratio of the peak module electric power to the total module heat absorption rate. These parameters were measured simultaneously to assure validity of the final efficiency value. A front surface filter, with spectral efficiency calculated from reflection data to be $\eta_{\text {Spectral }} \approx 79 \%$, is joined to the modules with optical epoxy. Table II shows the measured efficiency and electrical parameters of the $0.53-\mathrm{eV} \mathrm{InGaAsSb}$ TPV module. As predicted, $V_{\mathrm{OC}}, \mathrm{PD}$, and $\eta_{\mathrm{TPV}}$ decrease with increasing temperature $T_{\text {diode }}$. At $30{ }^{\circ} \mathrm{C}$, the average $0.53-\mathrm{eV}$ InGaAsSb TPV efficiency is only $\sim 70 \%$ of the practical limit to efficiency based on the intrinsic Auger recombination processes. The largest fractional difference in the experimental performance versus the intrinsic limits is due to the diode open-circuit voltage $\left(V_{\mathrm{OC}}=306 \mathrm{mV}\right.$ versus $\left.370 \mathrm{mV}\right)$, with the remainder attributed to spectral performance $\left(\eta_{\text {Spectral }}=79 \%\right.$ versus $87 \%$ ) and module $\mathrm{FF}(\mathrm{FF}=67 \%$ versus $74 \%)$ and the percent active area $\left(A_{\text {active }}=84 \%\right.$ versus $\left.90 \%\right)$. Based on the previous discussion, extrinsic recombination processes limit the InGaAsSb TPV diode $V_{\mathrm{OC}}$, making this the most significant barrier to reaching the practical efficiency limits.

\section{CONCLUSION}

A practical limit of $\eta_{\mathrm{TPV}}=28 \%$ and PD $=0.85 \mathrm{~W} / \mathrm{cm}^{2}$ for $0.53-\mathrm{eV}$ InGaAsSb TPV diodes operating at $T_{\text {radiator }}=950^{\circ} \mathrm{C}$ and $T_{\text {diode }}=27{ }^{\circ} \mathrm{C}$ is established. The most severe bound to low-bandgap TPV diode performance will be set by the intrinsic Auger limit to open-circuit voltage, which for $0.53-\mathrm{eV}$ $\mathrm{InGaAsSb}$ will be $V_{\mathrm{OC}}^{\max }=370 \mathrm{mV}$. The measured $\mathrm{InGaAsSb}$ TPV efficiency and PD indicate that InGaAsSb TPV diodes operate well below the intrinsic performance limits, primarily because the diode $V_{\mathrm{OC}}$ is dominated by extrinsic recombination processes such as through bulk defect levels. The semiempirical method used in this article can be applied to other TPV systems and operating conditions, where Auger recombination becomes particularly important if the diode operating temperature increases and/or the diode bandgap decreases, since the Auger recombination coefficients and intrinsic carrier density increase exponentially as $E_{G}$ is reduced and $T_{\text {diode }}$ is increased. Using the ranges of Auger coefficients versus $E_{G}$ reported in [7], our semi-empirical analysis determines that the intrinsic Auger recombination limits to open-circuit voltage and efficiency become more severe as the bandgap is reduced below $E_{G}<0.5 \mathrm{eV}$ for the temperatures considered in this paper.

\section{REFERENCES}

[1] P. F. Baldasaro, J. E. Raynolds, G. W. Charache, D. M. Depoy, C. T. Ballinger, T. Donovan, and J. M. Borrego, "Thermodynamic analysis of thermophotovoltaic efficiency and power density tradeoffs," J. Appl. Phys., vol. 89, no. 6, pp. 3319-3327, Mar. 2001

[2] T. J. Coutts and J. S. Ward, "Thermophotovoltaic and photovoltaic conversion at high-flux densities," IEEE Trans. Electron Devices, vol. 46, no. 10 , pp. 2145-2153, Oct. 1999.

[3] E. J. Brown, P. F. Baldasaro, S. R. Burger, L. R. Danielson, D. M. Depoy, J. M. Dolatowski, P. M. Fourspring, G. J. Nichols, and W. F. Topper, "The status of thermophotovoltaic energy conversion technology at Lockheed Martin Corporation," in Proc. Collect. Tech. Pap. Int. Int. Energy Convers. Eng. Conf.. Washington, DC: Amer. Inst. Aeronautics and Astronautics, 2004, vol. 2, pp. 1296-1315.

[4] B. Wernsman, R. G. Mahorter, R. Siergiej, S. D. Link, R. J. Wehrer, S. J. Belanger, P. Fourspring, S. Murray, F. Newman, D. Taylor, and T. Rahmlow, "Advanced thermophotovoltaic devices for space nuclear power systems," in Proc. STAIF, 2005, vol. 746, pp. 1441-1448.

[5] T. D. Rahmlow, J. E. Lazo-Wasem, E. J. Gratrix, P. M. Fourspring, and D. M. Depoy, "Design considerations and fabrication results for front surface TPV spectral control filters," in Proc. 6th Conf. Thermophotovoltaic Generation Elect., 2004, vol. 738, pp. 180-188.

[6] P. M. Fourspring, D. M. DePoy, T. D. Rahmlow, Jr., J. E. Lazo-Wasem, and E. J. Gratrix, "Optical coatings for thermophotovoltaic spectral control," presented at the Optical Interference Coatings, Tucson, AZ, 2004 ThE10. CD-ROM (The Optical Society of America, Washington, DC).

[7] G. W. Charache, P. F. Baldasaro, L. R. Danielson, D. M. Depoy, M. J. Freeman, C. A. Wang, H. K. Choi, D. Z. Garbuzov, R. U. Martinelli, V. Khalfin, S. Saroop, and J. M. Borego, "InGaAsSb thermophotovoltaic diode: Physics evaluation," J. Appl. Phys., vol. 85, no. 4, pp. 2247-2252, Feb. 1999.

[8] C. W. Hitchcock, R. J. Gutmann, J. M. Borego, I. B. Bhat, and G. W. Carache, "Antimonide-based devices for thermophotovoltaic applications," IEEE Trans. Electron Devices, vol. 46, no. 10, pp. 2154-2161, Oct. 1999.

[9] C. A. Wang, H. K. Choi, S. L Ransom, G. W. Charache, L. R. Danielson, and D. M. Depoy, "High-quantum-efficiency GaInAsSb/GaSb thermophotovoltaic devices," Appl. Phys. Lett., vol. 75, no. 9, pp. 1305-1307, Aug. 1999.

[10] H. K. Choi, C. A. Wang, G. W. Turner, M. J. Manfra, D. L. Spears, G. W. Charache, L. R. Danielson, and D. M. Depoy, "High performance GaInAsSb thermophotovoltaic devices with an AlGaAsSb window," Appl. Phys. Lett., vol. 71, no. 26, pp. 3758-3760, Dec. 1997.

[11] M. W. Dashiell, J. F. Beausang, G. Nichols, D. M. Depoy, L. R. Danielson, H. Ehsani, K. D. Rahner, J. Azarkevich, P. Talamo, E. Brown, S. Burger, P. Fourspring, W. Topper, P. F. Baldasaro, C. A. Wang, R. Huang, M. Connors, G. Turner, Z. Shellenbarger, G. Taylor, J. Li, R. Martinelli, D. Donetski, S. Anikeev, G. Belenky, S. Luryi, D. R. Taylor, and J. Hazel, "0.52 eV quaternary InGaAsSb thermophotovoltaic diode technology," in Proc. 6th Conf. Thermophotovoltaic Generation Elect., 2004, vol. 738, pp. 404-414.

[12] S. M. Sze, Physics of Semiconductor Devices, 2nd ed. Hoboken, NJ Wiley, 1981

[13] W. Shockley and H. A. Queisser, "Detailed balance limit of efficiency of p-n junction solar cells," J. Appl. Phys., vol. 32, no. 3, pp. 510-519, Mar. 1961.

[14] C. H. Henry, "Limiting efficiencies of ideal single and multiple energy gap terrestrial solar cells," J. Appl. Phys., vol. 51, no. 8, pp. 4494-4500, Aug. 1980.

[15] S. Anikeev, D. Donetski, G. Belenki, S. Luryi, C. A. Wang, J. M. Borrego, and G. Nichols, "Measurement of the Auger recombination rate in p-type $0.54 \mathrm{eV}$ GaInAsSb by time-resolved photoluminescence," Appl. Phys. Lett., vol. 83, no. 16, pp. 3317-3319, Oct. 2003.

[16] D. Donetski, S. Anikeev, G. Belenky, S. Luryi, C. A. Wang, and G. Nichols, "Reduction of interfacial recombination in GaInAsSb/GaSb double heterostructures," Appl. Phys. Lett., vol. 81, no. 25, pp. 47694771, Dec. 2002

[17] D. Donetski, S. Anikeev, N. Gu, G. Belenky, S. Luryi, C. A. Wang, D. A. Shiau, M. Dashiell, J. Beausang, and G. Nichols, "Analysis of recombination processes in $0.5-0.6 \mathrm{eV}$ epitaxial GaInAsSb lattice matched to GaSb," in Proc. 6th Conf. Thermophotovoltaic Generation Elect., 2004, vol. 738, pp. 320-328. 
[18] W. van Roosbroeke and W. Shockley, "Photon-radiative recombination of electrons and holes in germanium," Phys. Rev., vol. 94, no. 6, pp. 15581560, Jun. 1954.

[19] P. Asbeck, "Self-absorption effects on the radiative lifetime in GaAs-GaAlAs double heterostructures," J. Appl. Phys., vol. 48, no. 2, pp. 820-822, Feb. 1977.

[20] A. Marti, J. L. Balenzategui, and R. F. Reyna, "Photon recycling and Schockley's diode equation," J. Appl. Phys., vol. 82, no. 8, pp. 4067-4075, Oct. 1997.

[21] M. A. Green, "Limits on the open-circuit voltage and efficiency of silicon solar cells imposed by intrinsic Auger processes," IEEE Trans. Electron Devices, vol. ED-31, no. 5, pp. 671-678, May 1984.

[22] R. Huang, C. A. Wang, C. T. Harris, M. K. Connors, and D. A. Shiau, "Ohmic contacts to n-type GaSb and n-type GaInAsSb," J. Electron. Mater, vol. 33, no. 11, pp. 1406-1410, 2004.

[23] S. J. Adachi, "Optical dispersion relations for GaP, GaAs, GaSb, InP, InAs, InSb, AlGaAs, and InGaAsP," J. Appl. Phys., vol. 66, no. 12, pp. 6030-6040, Dec. 1989.

[24] R. K. Huang, C. A. Huang, M. K. Connors, and G. W. Turner, "Hybrid back surface reflector GaInAsSb thermophotovoltaic devices," in Proc. 6th Conf. Thermophotovoltaic Generation Elect., 2004, vol. 738, pp. 329-336.

[25] A. G. Milnes and A. Y. Polyakov, "Review: Gallium antimonide device related properties," Solid State Electron., vol. 36, no. 6, pp. 803-818, Jun. 1993.

[26] J. M. Olsen, R. K. Ahrenkiel, D. J. Dunlavy, B. Keyes, and A. E. Kibbler, "Ultralow recombination velocity at GaInP/GaAs heterointerfaces," Appl. Phys. Lett., vol. 55, no. 12, pp. 1208-1210, Sep. 1989.

[27] L. W. Molenkamp, G. L. M. Kampschoer, W. deLange, J. W. F. M. Maes, and P. J. Roksnoer, "Ultralong minority-carrier lifetimes in GaAs grown by low-pressure organometallic vapor-phase epitaxy," Appl. Phys. Lett., vol. 54, no. 20, pp. 1992-1994, May 1989.

[28] C. K. Gethers, C. T. Ballinger, and D. M. DePoy, "Thermophotovoltaic efficiency testing," in Proc. 4th Conf. Thermophotovoltaic Generation Elect., 1998, vol. 460, pp. 335-348.

[29] B. Wernsman, R. R. Siergiej, S. D. Link, R. G. Mahorter, M. N. Palmisiano, R. J. Wehrer, R. W. Shultz, R. L. Messham, S. Murray, C. S. Murray, F. Newman, D. Taylor, D. Depoy, and T. Rahmlow, "Greater than $20 \%$ radiant heat conversion efficiency of a thermophotovoltaic radiator/module system using reflective spectral control," IEEE Trans. Electron Devices, vol. 51, no. 3, pp. 512-516, Mar. 2004.

[30] C. A. Wang, H. K. Choi, D. C. Oakley, and G. W. Charache, "Expressions fit from mobility data of InGaAsSb layers grown on insulating GaAs substrates given in C.A.," J. Cryst. Growth, vol. 195, no. 1-4, p. 346, 1998.

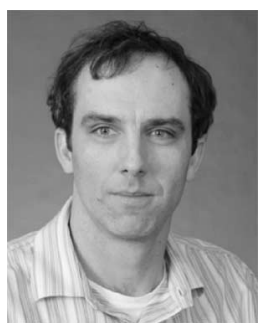

Michael W. Dashiell was born in Baltimore, MD, in 1970. He received the B.S., M.S., and Ph.D. degrees from the University of Delaware, Newark, in 1992, 1998, and 2001, respectively, all in electrical engineering.

From 1992 to 1996, he was a Research Engineer with AstroPower Inc. (currently GE Solar), where he developed high-efficiency silicon and GaAs solar photovoltaics. From 1997 to 2002, he was with the Department of Electrical Engineering, University of Delaware, and the Max-Planck-Institute for Solid State Physics, Stuttgart, Germany, where he conducted research regarding epitaxial growth, electrical and optical characterization of metastable silicon and silicon-carbide-based alloys, tunnel diodes, and self-assembled quantum dots. Since 2002, he has been an Electrical Engineer with the Knolls Atomic Power Laboratory, Niskayuna, NY (operated by Lockheed Martin Corporation, Schenectady, NY, for the U.S. Government), where he has been developing lowbandgap III-V thermophotovoltaic energy converters and high-performance power electronic motor drives. He is also an Adjunct Professor with Union Graduate College, Schenectady, and has authored or coauthored over 45 technical publications.

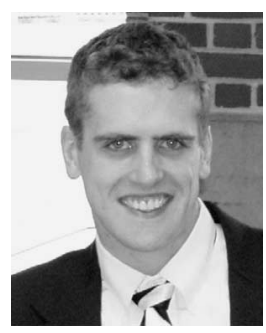

John F. Beausang was born in Hershey, PA, on November 11, 1976. He received the B.S. degree in engineering science from Pennsylvania State University, University Park, in 1999 and the M.S. degree in physics from Rensselaer Polytechnic Institute, Troy, NY, in 2002 . He is currently working toward the $\mathrm{Ph} . \mathrm{D}$. degree in physics at the University of Pennsylvania, Philadelphia.

Until 2004, he was with Lockheed Martin Corporation, Schenectady, NY, where he worked on thermophotovoltaic technology.

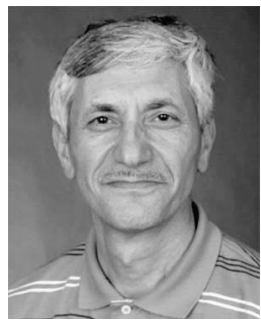

Hassan Ehsani received the B.S. and M.S. degrees in physics from the University of Tehran, Tehran, Iran, in 1974 and 1976, respectively, the M.S. degree from The University of Kansas, Lawrence, in 1984, and the Ph.D. degree from The University of Texas, Austin, both in electrical engineering, in 1988.

From 1976 to 1981 , he was a faculty member with the University of Tehran. From 1988 to 2000, he was a Research Scientist with Rensselaer Polytechnic Institute, Troy, NY. Since 2000, he has been a Senior Scientist with Knolls Atomic Power Laboratory, Niskayuna, NY (operated by Lockheed Martin Corporation, Schenectady, NY, for the U.S. Government). His research interests have covered a wide range of semiconductor physics and optoelectronic materials including organometallic chemical vapor deposition (OMCVD) growth of II-VI and III-V based compound semiconductors for infrared detectors, lasers, and thermophotovoltaics; metallization of group II-VI and III-V semiconductors, thermophotovoltaics, and solar cell devices; and processing, characterizations, and modeling. He is the author or coauthor of over 80 technical publications.

G. J. Nichols, photograph and biography not available at the time of publication.

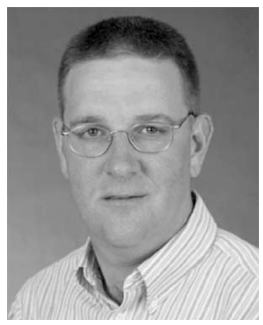

David M. Depoy received the B.S. and M.S. degrees from Rensselaer Polytechnic Institute, Troy, NY, in 1989 and 1993, respectively, both in mechanical engineering.

Since 1989, he has been with the Advanced Concepts Group, Knolls Atomic Power Laboratory, Niskayuna, NY (operated by Lockheed Martin Corporation, Schenectady, NY, for the U.S. Government), investigating direct energy conversion technologies. He has worked in the field of thermophotovoltaic (TPV) energy conversion for the past 13 years with emphasis on spectral control, characterization, performance modeling, and generator design. He is the author or coauthor of over 30 technical publications and holds five U.S. patents.

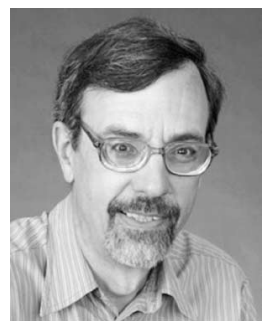

Lee R. Danielson received the B.S. degree from Iowa State University, Ames, in 1968, the M.S. degree from the University of Washington, Seattle, in 1969, and the Ph.D. degree from Washington State University, in 1977, all in physics.

From 1979 to 1988, he was with Thermo Electron Corporation, Waltham, MA, where he performed research on higher efficiency thermionic and thermoelectric energy conversion. Since 1989, he has been with Lockheed Martin Corporation, Schenectady, NY, where he has worked on thermoelectric and thermophotovoltaic energy conversion and has developed several electrical and thermal property measurement systems. 


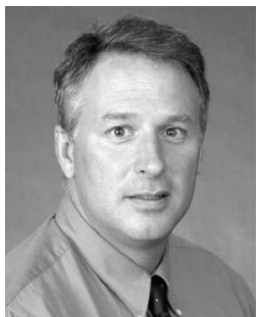

Phil Talamo received the B.S. degree in marine engineering systems from the United States Merchant Marine Academy, Kings Point, NY, in 1984.

In 1984, he joined Knolls Atomic Power Laboratory, Niskayuna, NY (operated by Lockheed Martin Corporation, Schenectady, NY, for the U.S. Government), where he is currently managing a group conducting research and development of advanced energy conversion technologies, specifically direct energy conversion. The bulk of the research effort is on thermophotovoltaics (TPV) with efforts to improve the conversion efficiency of high-performance semiconductor TPV devices and filters. His career started as an Operational Engineer at one of the nation's naval nuclear operating prototype, where naval personnel learn the fundamentals of operation prior to being assigned to one of the nation's nuclearpowered submarine or aircraft carrier. Prior to his current position, he managed the training program at the nuclear prototype, responsible for the training of all navy sailors.

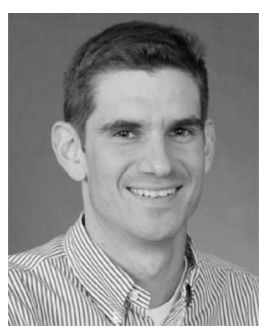

Kevin D. Rahner received the B.S. degree in physics from the University at Albany, State University of New York (SUNY), Albany, and the M.S. degree in electrical engineering from Binghamton University, SUNY.

Since 2002, he has been an Engineer with Lockheed Martin Corporation, Schenectady, NY, working on electrical performance modeling and radiative heat transfer modeling of TPV systems.

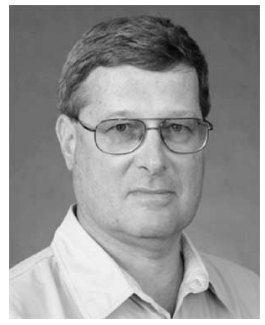

Edward J. Brown received the B.S. degree in physics and the M.S. degree in physics from the State University of New York at New Paltz in 1979 and the M.S. degree in nuclear engineering from Rensselaer Polytechnic Institute, Troy, NY, in 1983.

In 1982, he joined the technical staff with Knolls Atomic Power Laboratory, Niskayuna, NY (operated by Lockheed Martin Corporation, Schenectady, NY, for the U.S. Government), working in the areas of reactor core design, reactor safety analysis, and experimental reactor operations. In 1990, he joined the Advanced Concepts Group working on direct energy conversion. Since 1997, he has supervised the energy conversion testing program supporting the development of thermophotovoltaic energy conversion technology. He holds four U.S. patents. His areas of research interest include direct energy conversion, nuclear reactor core design, and reactor dynamics modeling.

Mr. Brown is a member of Tau Beta Pi and Alpha Nu Sigma and was the President of the NENY Section of the American Nuclear Society.

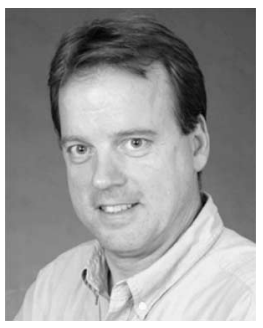

Steven R. Burger received the B.S. degree in chemical engineering from Manhattan College, Riverdale, NY, in 1986 and the M.S. degree in mechanical engineering from Union College, Schenectady, NY, in 1986 .

Since 1982, he has been with the Knolls Atomic Power Laboratory, Niskayuna, NY (operated by Lockheed Martin Corporation, Schenectady, for the U.S. Government), where he is currently a Senior Engineer in the Advanced Components and Systems Unit working on turbomachinery design. He is the author or coauthor of ten technical publications. His development and work interests have covered a wide range of engineering disciplines including semiconductor packaging development for direct energy conversion devices, nondestructive test development for reactor plant components, reactor plant fluid system design, and reactor plant equipment maintenance and modification.

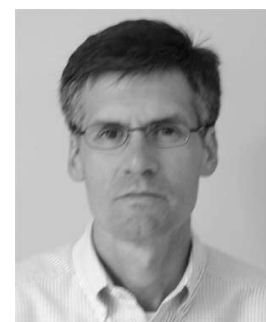

Patrick M. Fourspring received the B.S. and M.S. degrees in structural mechanics from Clemson University, Clemson, SC, in 1982 and 1986, respectively, and the $\mathrm{Ph} . \mathrm{D}$. degree in engineering science and mechanics from the Pennsylvania State University, University Park, in 1997.

His entire career has been associated with nuclear power. From 1980 to 1990, he was with Duke Power (now Duke Energy), where he was a Cooperative Education Student supporting system modifications for operating nuclear power stations and a Design Engineer responsible for the identification and implementation of technology to improve the performance of nuclear power stations. In 1994, he joined the Knolls Atomic Power Laboratory, Niskayuna, NY (operated by Lockheed Martin Corporation, Schenectady, NY, for the U.S. Government) and has completed numerous mechanical analyses of the nuclear reactor components as well as assessments of various nuclear reactor configurations. Since 2003 , he has been leading the development of spectral control technology for thermophotovoltaic energy conversion of heat from a nuclear reactor source.

Dr. Fourspring is a member of the American Society of Mechanical Engineers (ASME). He is a Registered Professional Engineer.

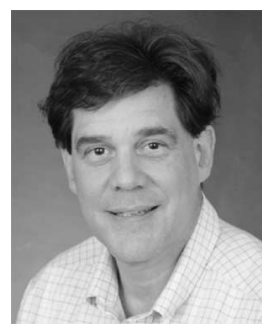

William F. Topper, Jr. received the B.S. degree in mechanical engineering from Cornell University, Ithaca, NY, in 1971, and the M.S. degree in mechanical engineering from Rensselaer Polytechnic Institute, Troy, NY, in 1974. He is currently working toward the Ph.D. degree at Rensselaer Polytechnic Institute.

He has 35 years of professional experience covering developmental testing of gas turbine engine components with AVCO Lycoming; program management for manufacturing, development, and design of nuclear system components with General Electric; and design and professional engineering certification of medical waste incinerator and energy recovery systems with WFT Engineering Services. He is currently with Lockheed Martin Corporation, Schenectady, NY, and has been in several positions providing technical customer support, performing component design, and working on development and testing of nuclear power plant equipment His current position involves the development of energy conversion systems and components and the design and operation of developmental test apparatus for advanced mass transport system components.

P. F. Baldasaro, photograph and biography not available at the time of publication.

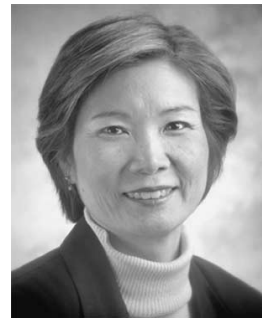

Christine A. Wang received the S.B., M.S., and $\mathrm{Ph} . \mathrm{D}$. degrees from the Materials Science and Engineering Department, Massachusetts Institute of Technology, Lexington, in 1977, 1978, and 1984, respectively.

In 1984, she joined Lincoln Laboratory, Massachusetts Institute of Technology, Cambridge, where she is currently a Senior Staff Member in the ElectroOptical Materials and Devices Group and works on III-V materials grown by organometallic vapor phase epitaxy (OMVPE) for advanced optoelectronic devices. She is the author or coauthor of over 140 technical publications and holds four U.S. patents. Her research interests include gas transport and design of OMVPE reactors, growth and materials characterization of diode lasers, thermophotovoltaic devices, and detectors.

Dr. Wang is a member of Tau Beta Pi, Sigma Xi, and the Materials Research Society. She is currently the Vice-President of the American Association of Crystal Growth. 


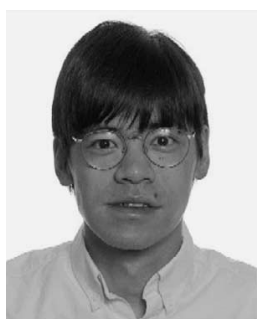

Robin K. Huang (M'03) received the S.B. degree in physics with electrical engineering from the Massachusetts Institute of Technology (MIT), Cambridge, in 1995, and the M.S. degree in electrical engineering and the Ph.D. degree in applied physics from Stanford University, Stanford, CA, in 1997 and 2000, respectively. In 2000, he joined Lincoln Laboratory, MIT, where he is currently a Staff Member. He is the author or coauthor of over 35 technical publications. His research interests include high-power near-infrared semiconductor diode lasers, thermophotovoltaic devices, mid-IR diode lasers, and vertical cavity surface emitting lasers (VCSELs)

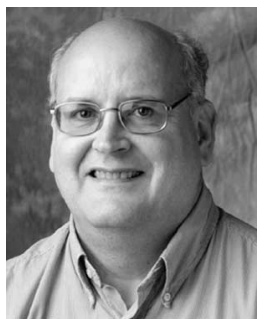

Michael K. Connors received the B.S. degree in biological science and environmental science from the University of Massachusetts, Lowell, in 1977.

In 1977, he joined Lincoln Laboratory, Massachusetts Institute of Technology, Cambridge, where he is currently an Assistant Staff Member in the Electro-Optical Materials and Devices Group. He is the coauthor of over 45 publications. His research interests include development of device fabrication processes, reactive ion etching of semiconductor materials, and thin-film deposition of dielectric and metal coatings.

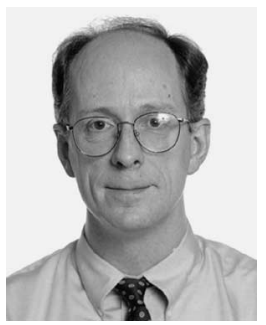

George W. Turner (M'00) received the B.S., M.S. and Ph.D. degrees in electrical engineering from Johns Hopkins University, Baltimore, MD, in 1972 1975 , and 1979, respectively.

In 1979, he joined Lincoln Laboratory, Massachusetts Institute of Technology, Cambridge, where he has been a Staff Member in a number of different groups in the Solid-State Division. He is currently an Assistant Leader in the Electro-Optical Materials and Devices Group. He authored or coauthored several book chapters, over 125 technical publications, and holds four U.S. patents. His research interests have covered a wide range of device fabrication and material growth areas, including avalanche photodiodes, direct energy conversion devices, and mid-infrared lasers.

Zane A. Shellenbarger received the M.S.E.E. degree from the University of Delaware, Newark, and the B.A. degree in physics from Cornell University, Ithaca, NY.

He was with AstroPower Inc. and Structured Materials Inc. for 11 years, working on the development of epitaxial growth and the fabrication of thermophotovoltaics, solar cells, infrared detectors, and LEDs. In 2000, he joined Sarnoff Corporation, Princeton, NJ, where he is currently a Member of Technical Staff and has been responsible for the epitaxial growth of InP-, GaAs-, and GaSb-based lasers, thermophotovoltaic cells, and other optoelectronic devices. He is the author of over 40 technical publications in journals and conference proceedings on laser diodes, photovoltaics, thermophotovoltaics, infrared detectors, and other optoelectronic devices. His technical expertise is in the epitaxial growth of semiconductor materials by metalorganic chemical vapor deposition and the characterization of semiconductor materials.

Gordon Taylor (S'76-M'76) received the B.S., M.S., and Ph.D. degrees in electrical engineering (solid state device specialization) from Rutgers University, Camden, NJ, in 1969, 1972, and 1976, respectively.

He has been with Sarnoff Corporation, Princeton, NJ, for over 30 years.
Jizhong Li received the M.S. degree in optoelectronics and information engineering from Shandong University, Qingdao, China, in 1989 and the Ph.D. degree in solid-state physics from Kansas State University, Manhattan, in 1999.

Before 1994, he was an Associate Professor with the Department of Physics, Qufu Normal University, Qufu, China, where he conducted research on laser beam modulation and polarization technologies. During his postdoctoral research with North Carolina State University in 2000, he conducted AlGaN/GaN material growths by metal organic chemical vapor deposition (MOCVD) for the fabrication of solar blind (250-280 nm) detector arrays. From 2000 to 2005, he was a member of Technical Staff with Sarnoff Corporation, where he conducted the development of various III-V compound materials for fabricating high power lasers and thermophotovoltaic devices. He is currently a Research Scientist with the Center for Optical Technologies, Lehigh University, Bethlehem, PA.

Ramon Martinelli (S'59-M'84) received the A.B. and M.S. degrees in electrical engineering from Dartmouth College, Hanover, NH, in 1960 and 1961, respectively, and the Ph.D. degree in electrical engineering from Princeton University, Princeton, NJ, in 1965.

He is a Distinguished Member of Technical Staff with Sarnoff Corporation, Princeton, NJ.

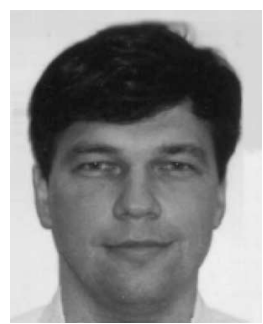

Dmitry Donetski (SM'98-M'97) received the Diploma (with Honors) and the Ph.D. degree in physics from St. Petersburg State Technical University, St. Petersburg, Russia, in 1987 and 1996, respectively, and the Ph.D. degree in electrical engineering from the State University of New York, Stony Brook, in 2000 .

From 1987 to 1996, he was with the Department of Semiconductor Physics and Nanoelectronics, St. Petersburg State Technical University, working on the design of far-infrared semiconductor lasers and electrooptic modulators on hot carriers. In 1996, he joined the Optoelectronics Group, Electronics and Communications Engineering Department, State University of New York, Stony Brook. His research is focused on the design and technology of optoelectronic devices including thermophotovoltaic cells, midinfrared laser diodes, and laser diode arrays. He has 50 publications in referred journals and conference proceedings.

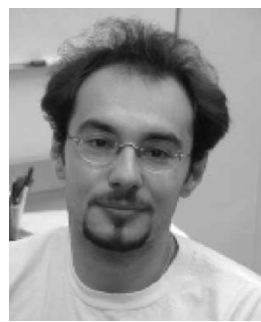

Sergei Anikeev received the M.Sc. degree (with the MSU Graduation medal) in physics from Lomonosov Moscow State University (MSU), Moscow, Russia, in 2000, and the Ph.D. degree in electrical engineering from State University of New York, Stony Brook, in 2006.

In 1998, he was awarded the scholarship of Teaching-Research Center "Fundamental Optics and Spectroscopy." He is currently with the State University of New York. He authored or coauthored 15 papers in scientific journals and conference proceedings. His research interests include experimental and analytical study of energy relaxation processes in semiconductors and physics of thermophotovoltaic devices. 


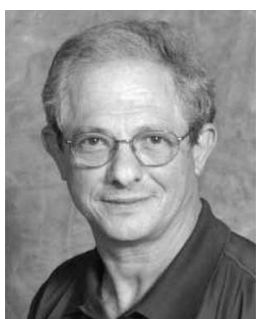

Gregory L. Belenky (M'95-SM'96-F'05) received the Doctor of Physics and Mathematics degree in Russia.

In 1991, he was with AT\&T Bell Labs, Murray Hill, NJ. In 1995, he joined the State University of New York, Stony Brook, where he is currently a Professor in the Department of Electrical and Computer Engineering. He has published over 140 papers and four reviews and filed four U.S. patents dealing with the physics of two-dimensional structures and physics and design of photonic devices. His current interests include physics of semiconductors and the design and working performance of semiconductor lasers and optoelectronic systems.

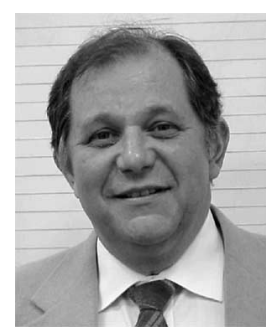

Serge Luryi (M'81-SM'85-F'89) received the $\mathrm{Ph} . \mathrm{D}$. degree in physics from the University of Toronto, Ontario, Canada, in 1978. His doctoral thesis was on the theoretical studies of intermolecular interactions in solid hydrogen.

In 1980, he was with Bell Laboratories, Murray Hill, NJ, and became interested in the physics and technology of semiconductor devices. In 1994, he joined the State University of New York, Stony Brook, where he currently chairs the Electrical and Computer Engineering Department. In 1995, he organized an advanced research workshop on the "Future Trends in Microelectronic," (FTM) which grew into a regular series. The fifth FTM workshop took place in June 2006 on the island of Crete, Greece (complete information can be found at www.ee.sunysb.edu/ serge/FTM.html). He is also the Founding Director of the NY State Center for Advanced Sensor Technology (Sensor CAT). He has published over 200 scientific papers and holds 43 U.S. patents.

Dr. Luryi was elected Fellow of the IEEE for contributions in the field of heterojunction devices in 1989, received the Distinguished Member of Technical Staff award from Bell Laboratories in 1990, and was elected Fellow of the American Physical Society in 1993 for contributions to the theory of electron transport in low-dimensional systems and invention of novel electron devices. In 2003, he was appointed to the rank of Distinguished Professor by the Board of Trustees of the State University of New York. He served as the Editor of IEEE TRANSACTIONS ON ELECTRON DEVICES from 1986 to 1990. 